\title{
Multiphase Airlift Pumps for Water circulation in Fish Farms
}

\author{
Shaker Bukhari, Joshua Rosettani, Wael Ahmed \\ University of Guelph \\ 50 Stone Rd E, Guelph, Canada \\ shaker@uoguelph.ca; jrosetta@uoguelph.ca, ahmedw@uoguelph.ca
}

\begin{abstract}
The potential use of an airlift pump to circulate and oxygenate water in an aquaculture facility is experimentally investigated. Currently, two systems are used in fish farms to perform the same function. These include air-stones for oxygenation and centrifugal or submersible pumps for water circulation. Airlift pumps operating under multiphase flow condition are proposed in order to replace these two systems with a single system. This solution offers a better energy efficient system while achieving ideal water quality for fish production. Airlift pump was designed and tested in a fish farm facility located at Aberfoyle, Ontario. The data for local water velocities and the required air injection flow rates for 4-units airlift pump arrangement was collected. The pump performance data for the dual injection airlift was compared to the airlift pump model developed for slug flow pattern. These tests were used to determine the appropriate sizing of the airlift pumps required for the water circulation in the raceways.
\end{abstract}

Keywords: Airlift Pump, Aquaculture, Raceways, Two-Phase Flow, Dual Injection.

\section{Introduction}

In airlift pump, liquid or mixture of liquid and solids flow when air is injected at the bottom of a vertical pipe and a multiphase mixture reaches the top part of this vertical pipe know as a pump riser. Different injections methods in airlift systems are presented by Badr and Ahmed [1] and the pump performance is related to the type of injectors used. Badr and Ahmed [1] presented an injector that consists of two air chambers to supply air in both radial and axial direction. The radial injection is known to improve mass transfer and can be used to increase the oxygen levels in the water. The oxygen level in the water is crucial for the animal health and the success of fish production. Also, water circulation is important to avoid stagnation which can lead to multiple problems including the accumulation of excrement and other harmful particles that cause fish infection. Moving current in the raceways is also important for muscle build up and leads to a better yield form feed to biomass produced $[2,3]$.

Airlift performance is highly dependent on the two-phase flow patterns in the pump riser as early reported by Kassab et al. [4]. These patterns are bubbly flow, slug flow, churn flow and annular flows. The transition between these flow patterns such as bubbly-slug or slug-churn flow have been also reported. The pump performance under the slug flow pattern is considered to be optimal operation. Under this pattern, the air acts as pistons which are the slugs that push the water column with maximum buoyant forces. They have developed a theoretical airlift pump model using two-phase separated flow model. Their model incorporated the slip between the two phases and effect of variable two-phase coefficient of friction. The model is also validated using experiments for different air flow rates, submergence ratios and pressure heads. The performance characteristics of the later dual injection airlift pump developed by Ahmed et al. [5] found to be predicted using the same model of Kassab at al. [4]. In this model the slug flow correlation for slip ratio is also used to predict the pump performance.

In this study, the performance data was collected for airlift pumps commercialized by FloNergia for different pump diameters. The pumps were tested in a fish farm located at Aberfoyle, Ontario. In this farm, the construction of the pump arrangement was selected to establish a raceway for a rainbow trout using a high grade equipment and air blowers. The velocity across the raceways that ran with the older technology airlifts was recorded. These older airlifts depend only on an air-stone injector that is imbedded into a larger pipe and acts more like an oxygenation device than a pump. 


\section{Baseline Data for Raceway Velocities}

The dual injection airlifts were installed in one of the two smaller raceways while the other raceway had the older system airlift technology installed. The raceways are constructed with a metal framing and a 5-cm sheet of plastic that wraps the frame. The larger raceways can accommodate 3000 rainbow trout at once. They are built on floating docks that are secured to the shore. The dimensions are listed in meters as shown in Figure 1. The velocities were measured at standard conditions for the raceway operation. To measure the velocity, an ultrasonic flow tracking instrument was used. The Bubbler airlifts consists of two co-axial pipes with an outlet at the surface of the water. Air is injected through the smaller pipe and the water and air are pushed to the top. These types of airlifts provide the required aeration however, they lack ideal water flow velocity. For raceways and other aquaculture systems that are installed in open waters, oxygen levels are not a major concern. Water circulation is more important parameter when dealing with these types of raceways.
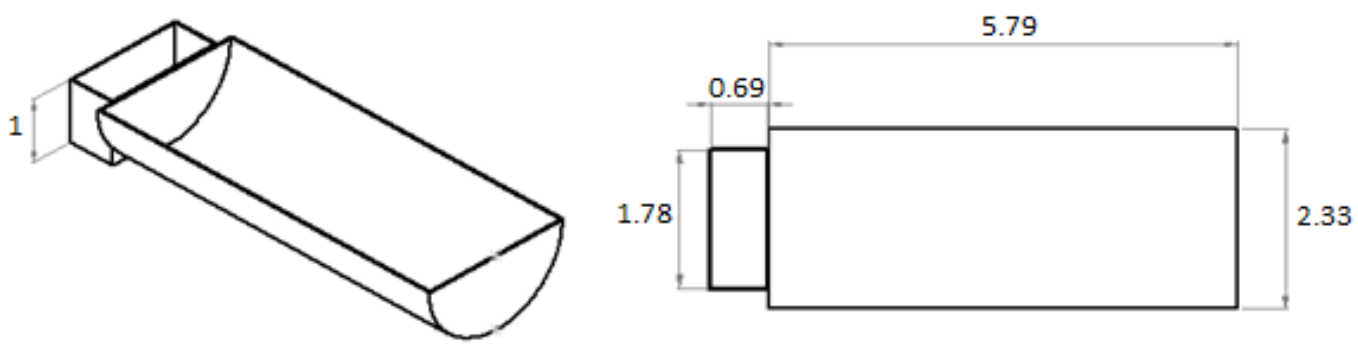

Fig 1: Illustration of Raceway dimensions.

The velocity is measured 1-m downstream from the water flow outlet. Four points were measured in line cross the raceway at the same distance away from the flow outlet. Three readings were taken at each point and an average was recorded for repeatability. The airflow rate in this measurement was 700 LPM which was the highest flow rate possible from the airline to the old airlifts. The results of the velocity readings are in the Table 1.

Table 1: Velocity Readings of bubbler Airlifts.

\begin{tabular}{|l|c|c|c|c|}
\hline Location & $0.6 \mathrm{~m}$ & $1.1 \mathrm{~m}$ & $1.8 \mathrm{~m}$ & $2.2 \mathrm{~m}$ \\
\hline Average Velocity (cm/s) & 2.30 & 10.13 & 4.33 & 1.43 \\
\hline
\end{tabular}

\section{New Setup Design}

The dual injection airlift pumps are designed based on the required water flow rate in the raceway. The pumps were connected to open ended PVC pipes with the same diameter as the pump it's connected to. Two setups were built one to test airlift performance of different diameters, the other to test raceway velocities. What is important was that the total length of the setups must be the same to achieve the same submergence ratio. The parameter that is being investigated is the change in airlifts geometry and how that affects performance. The setup was put on a custom built frame and an elbow was attached to the top making sure the proper length of $2.08-\mathrm{m}$ was achieved. The frame had to accommodate and interchange all the diameter sizes tested $0.05-\mathrm{m}, 0.10-\mathrm{m}, 0.15-\mathrm{m}$, and $0.20-\mathrm{m}$. The airlift is installed to the frame and is submerged to the correct depth which is $1.78-\mathrm{m}$ which is 0.85 submergence ratio. Two airlines are connected with two separate values to control the flow rate to each injector separately. A schematic of the setup is shown in Figure 2.

\section{Results}

Once the required airflow rate is set through the valves the experiment run can begin. The process must be done by at least two people, one person collects the water and one person would time and write down the results. To time the run a simple stopwatch is used. A volume of water is collected over a period of time to determine the total mass flow rate of lifted water out of the pump. For each air flow rate selected three runs of the experiment were performed for repeatability. The point shown in the graph is an average of the three readings with the percentage error of $2.81 \%$. Once all the possible flow range is complete the frame is pulled out of the water, and the next airlift pump is installed on to the frame and the experiment is repeated. The sample data below is for the $10-\mathrm{cm}$ airlift pump and compared to the theoretical model 
developed by [4]. The 10-cm pump has the best potential out of the other dimensions to create similar velocities to the velocities created by the old airlifts.

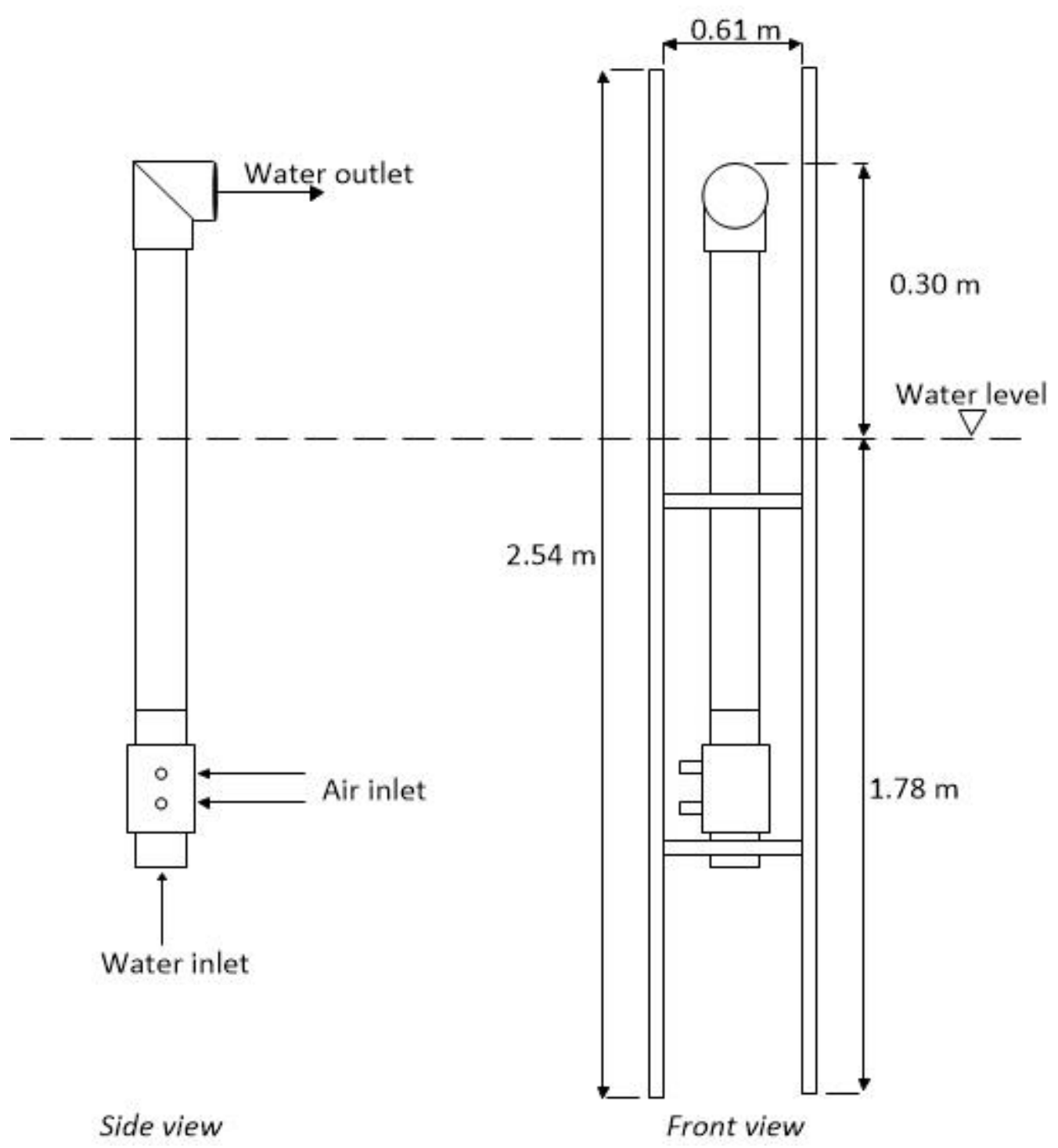

Fig 2: Performance testing frame dimensions in meters. 


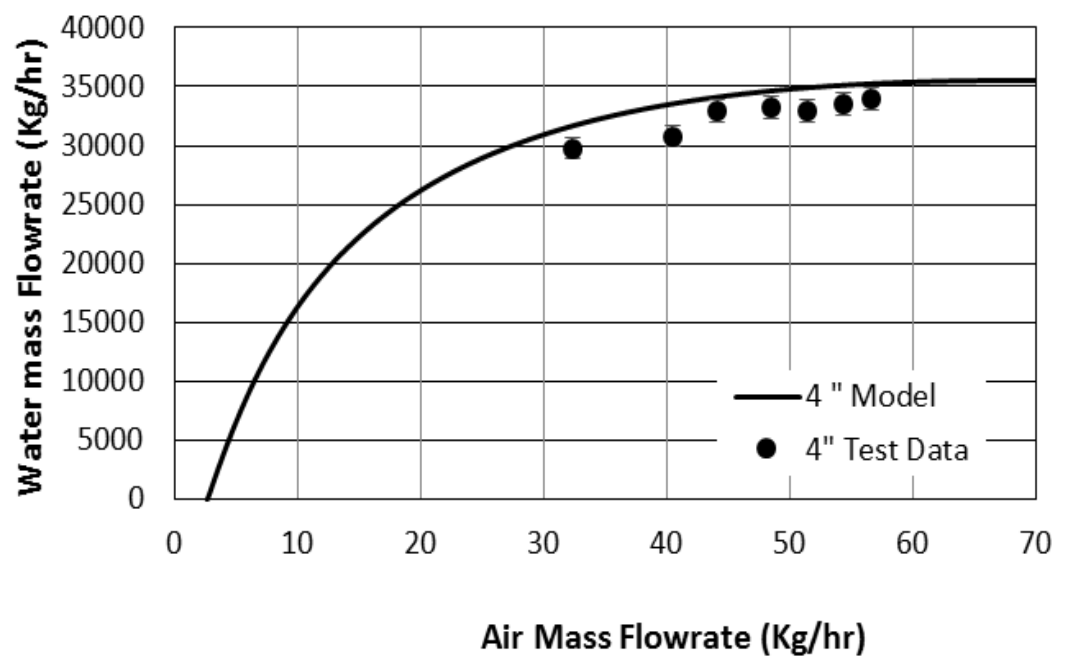

Fig. 3: Water flow performance of airlift pump $\mathrm{Sr}=0.85$.

The second setup was constructed with four 10-cm diameter Airlift pumps connected in a parallel network. Dedicated valves are in the network for axial and radial injection of each pump making a total of 8 valves in the system. This allows for more control over the air injection required. The network was put onto a metal frame as shown in Figure 5. The velocity measurements were taken at 11 points along and across the raceway. The data recorded is displayed in table format and on a gradient on the raceway. The air flowrate that was used in the velocity readings shown was 1600 LPM which is the highest airflow rates possible in the system. Higher air flowrates were achieved because the used airlift pumps offer less pressure drop.

Table 3: Velocity readings in the raceway operated by airlift pumps.

\begin{tabular}{|l|c|c|c|c|c|c|c|c|c|c|c|}
\hline Location & $\mathbf{1}$ & $\mathbf{2}$ & $\mathbf{3}$ & $\mathbf{4}$ & $\mathbf{5}$ & $\mathbf{6}$ & $\mathbf{7}$ & $\mathbf{8}$ & $\mathbf{9}$ & $\mathbf{1 0}$ & $\mathbf{1 1}$ \\
\hline Average Velocity $\mathbf{( c m} / \mathbf{s})$ & -1.20 & 8.86 & 42.5 & 38.6 & 17.30 & 18.83 & 33.06 & 24.66 & 3.16 & 8.63 & 18.70 \\
\hline
\end{tabular}

\section{Conclusion}

The experimental results prove that large dimeter airlift pumps can be used to achieve the required water flow rates for raceways. Comparing between the velocities achieved using the airlift pump and the velocities required for the raceway, it is noticed that higher velocities can be achieved with similar air injection flow rate in the old system. The technology offered by Flonergia for airlift pumps found to provide adequate water circulation while providing aeration in the raceway. This can help improve the production efficiencies of fish farms while lowering the overall energy consumption and creating a better yield rate of fish production. 


$\mathrm{cm} / \mathrm{s}$
0
5
10
15
20
25
30
35
40
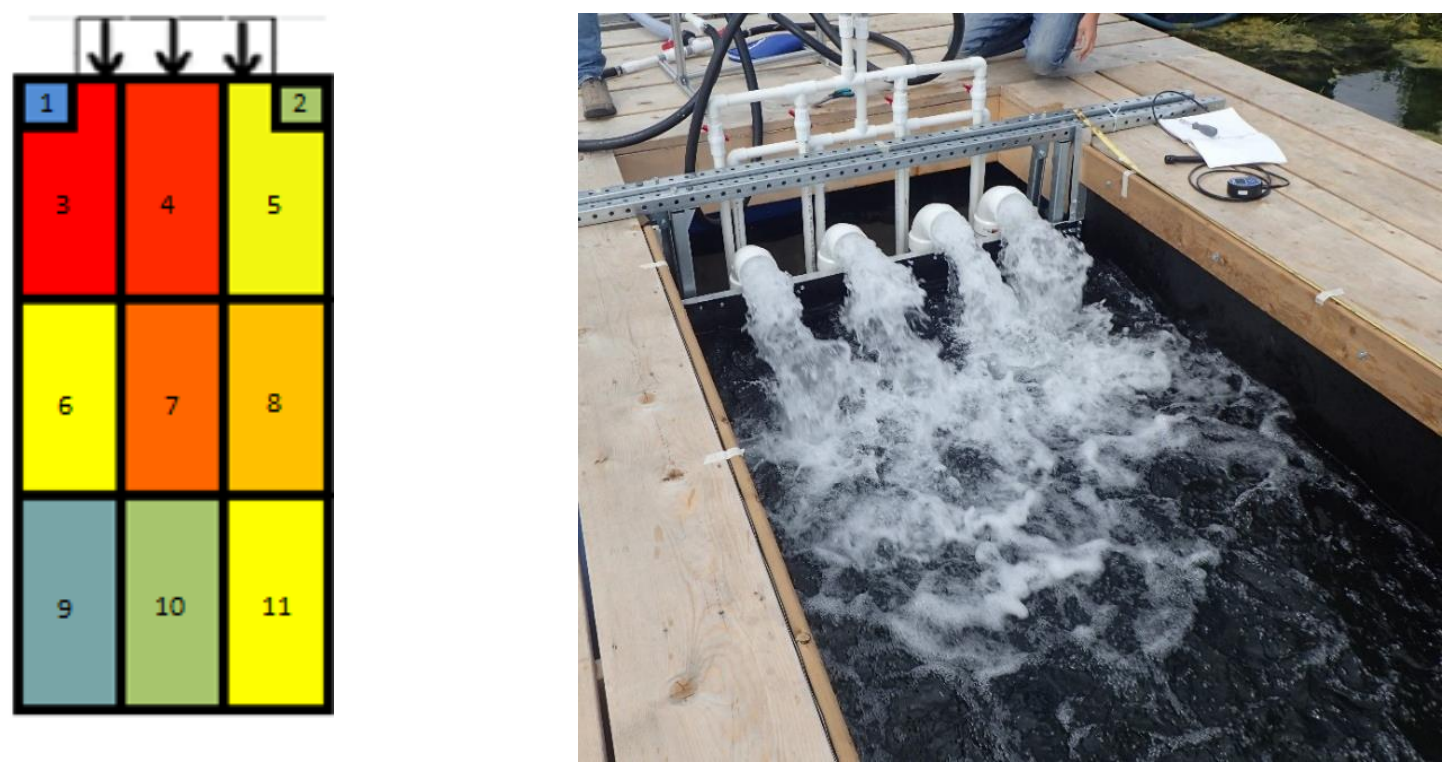

Fig. 4: Velocity gradient of raceway with dual injection airlift.

\section{Acknowledgements}

The authors wish to acknowledge the support received from the Ontario Ministry of Agriculture and Rural Affairs (OMAFRA) under the Gryphon's LAAIR (Leading to Accelerated Adoption of Innovative Research) grant.

\section{Reference.}

[1] H. M. Badr and W. H. Ahmed, "Dual Injection Airlift Pump," US 2012/0308407 A1, 2012.

[2] D. J. Reinemann, "A Theoretical and Experimental Study of Airlift Pumping and Aeration With Reference To Aquacultural Applications," no. August, pp. 1-111, 1987.

[3] J. C. Loyless and R. F. Malone, "Evaluation of air-lift pump capabilities for water delivery, aeration, and degasification for application to recirculating aquaculture systems," Aquac. Eng., vol. 18, no. 2, pp. 117-133, 1998.

[4] S. Z. Kassab, H. A. Kandil, H. A. Warda, and W. H. Ahmed, "Air-lift pumps characteristics under two-phase flow conditions," Int. J. Heat Fluid Flow, vol. 30, no. 1, pp. 88-98, 2009.

[5] W. H. Ahmed, A. M. Aman, H. M. Badr, and A. M. Al-Qutub, "Air injection methods: The key to a better performance of airlift pumps," Exp. Therm. Fluid Sci., vol. 70, pp. 354-365, 2016.

[6] Z. Gephardt, J. D'aloia, and G. Ndonga, "Airlift Technology Models for Aquaculture Applications with a Focus on Latin America: Predictive Tools for System Performance and Optimization,” Laccei.Org, pp. 1-9, 2009. 